\title{
Metástasis tardía de cáncer de mama derecha a pelvis renal y uréter derecho. Informe de un caso clínico
}

\author{
Late metastasis of right breast cancer to renal pelvis and right ureter. A case report
}

Laura C. Mejía-Ríos*, Roberto Ramírez-Vega, Jorge Reyes-Arroyo, Víctor Salgado-Arroyo, Carlos O. Castillo-Canto y Álvaro J. Montiel-Jarquín

Servicio de Urología, Unidad Médica de Alta Especialidad, Hospital de Especialidades de Puebla, Centro Médico Nacional General de División Manuel Ávila Camacho, Instituto Mexicano del Seguro Social, Puebla, México

\section{Resumen}

Antecedentes: Las metástasis de mama a uréter son extremadamente raras y la mayoría son asintomáticas. Caso clínico: Mujer de 67 años, con cáncer de mama derecha EC IA luminal $A$ de 5 años de evolución. Presentó infección de vías urinarias de repetición, hematuria macroscópica total y dolor renal derecho. La tomografía abdominopélvica mostró dilatación del cáliz superior y defecto de llenado en la pelvis renal derechos. Se le realizó nefroureterectomía radical derecha, rodete vesical. El reporte histopatológico fue metástasis de carcinoma infiltrante con afectación de pelvis renal y uréter. Conclusiones: La metástasis tardía del cáncer de mama al uréter y la pelvis es rara.

Palabras clave: Cáncer de mama. Metástasis tardía. Pelvis renal. Uréter.

\begin{abstract}
Background: Breast metastases to ureter are extremely rare. Most are asymptomatic. Case report: $A$ 67-year-old woman with 5 years of evolution, with right breast cancer stage IA luminal A. She presented repeated urinary tract infection, total macroscopic hematuria and pain in the right renal fossa. The computed tomography showed dilation of the upper calyx and filling defect in the renal pelvis. A right laparoscopic radical nephroureterectomy was realized; the histopathological report was metastasis of infiltrating carcinoma without specific pattern involving renal pelvis and ureter. Conclusions: Late metastasis of breast cancer to ureter and pelvis are rare.
\end{abstract}

Key words: Breast cancer. Late metastasis. Pelvis renal. Ureter.

\section{Introducción}

El cáncer de mama es el que se diagnostica más frecuentemente en todo el mundo y es la causa principal de muerte relacionada con cáncer en las mujeres. El $69 \%$ de las muertes por esta enfermedad ocurren en países en vías de desarrollo, donde la mayoría de los casos se diagnostican en fases avanzadas, lo que dificulta su tratamiento exitoso y conlleva un mal pronóstico'. Anualmente se diagnostican

\section{Correspondencia \\ *Laura C. Mejía-Rios \\ 2 norte, 2004}

Col. Centro

C.P. 72000 , Puebla, Pue., México

E-mail: lau.coretta@gmail.com
Fecha de recepción: 20-09-2019

Cir Cir. 2020;88(S1):83-86

Fecha de aceptación: 26-11-2019

DOI: $10.24875 / C I R U .19001584$
Contents available at PubMed

www.cirugiaycirujanos.com

0009-7411/C 2019 Academia Mexicana de Cirugía. Publicado por Permanyer. Este es un artículo open access bajo la licencia CC BY-NC-ND (http://creativecommons.org/licenses/by-nc-nd/4.0/). 
alrededor de 1.7 millones de casos de cáncer de mama, con aproximadamente un caso nuevo cada 18 segundos ${ }^{2}$.

Se han establecido numerosos factores de riesgo, entre los cuales se encuentran el sexo femenino, los antecedentes familiares de cáncer de mama a una edad temprana, la menarca temprana, la menopausia tardía, la edad mayor al primer parto, el uso prolongado de remplazo hormonal, la exposición previa a radiación terapéutica en el tórax, la enfermedad mamaria benigna y las mutaciones genéticas.

De acuerdo con las guías de práctica clínica de la National Comprehensive Cancer Network de 2019, en la vigilancia y el seguimiento del cáncer de mama se debe llevar a cabo anamnesis y exploración física de una a cuatro veces al año durante los primeros 5 años, y posteriormente cada año. En el manejo posquirúrgico se debe educar y monitorizar el manejo del linfedema. La mamografía realizará anualmente. En ausencia de signos y síntomas sugestivos de recurrencia no está indicado el uso de estudios de laboratorio y gabinete para la detección de metástasis.

Las mujeres en tratamiento con tamoxifeno deberán realizarse una evaluación ginecológica anual. En aquellas tratadas con un inhibidor de la aromatasa se debe realizar monitoreo de la salud ósea con una determinación de la densidad mineral ósea al inicio y periódicamente.

Los factores de riesgo más comunes que influyen en el proceso de metástasis del cáncer de mama son el tamaño del tumor, el grado histológico, el estadio nodal y la presencia de receptores estrógeno-progesterona positivos; la propensión del cáncer de mama para metástasis a distancia depende de su estirpe molecular ${ }^{3}$.

Actualmente, la prevalencia y el patrón de las metástasis del carcinoma de mama pueden estar cambiando debido al uso de quimioterapia, ya que la sobrevida de estas pacientes es cada vez mayor ${ }^{4}$.

Los sitios de metástasis más comunes son los ganglios linfáticos regionales, además del pulmón, el hueso, el hígado y la pleura. El tracto urinario es un sitio inusual para la propagación de la enfermedad, y el riñón es más afectado que el uréter y la vejiga ${ }^{5}$. Caskey, et al. ${ }^{6}$ reportan metástasis al riñón en un $11-27 \%$, a vejiga en un $2.4-5 \%$ y a uréter en un $1-9 \%$.

La obstrucción ureteral en el carcinoma de mama se divide en dos categorías: la confinada a sitios ureterales y la que incluye sitios periureterales con involucro pélvico y abdominal más extenso.
El objetivo de este trabajo de investigación es presentar un caso clínico de metástasis tardía de cáncer de mama derecha a pelvis renal y uréter homolaterales.

\section{Caso clínico}

Mujer de 67 años, sordomuda, con diabetes mellitus tipo 2 e hipertensión arterial sistémica de 1 año de diagnóstico. Se le diagnosticó cáncer de mama derecha EC IA a finales del año 2014 y se le realizó cuandrantectomía derecha y disección radical de axila. El reporte histopatológico fue carcinoma ductal infiltrante luminal $A$, moderadamente diferenciado, con suma de Sacrff-Bloom-Richardson $6(3+3)$, receptores de estrógenos positivo (100\%), receptores de progesterona positivo (100\%), receptores del factor de crecimiento epidérmico tipo 2 negativo (0) (Fig. 1); 7/7 ganglios linfáticos negativos a malignidad. Se manejó con quimioterapia (inhibidor de la aromatasa letrozol, $2.5 \mathrm{mg} / 24 \mathrm{~h}$ ) y 25 sesiones de radioterapia 65 Gy y sobredosis en el lecho tumoral. Durante el seguimiento no hubo datos de recurrencia ni progresión, tanto clínica como por laboratorio y gabinete.

En el año 2019 la paciente fue atendida por infecciones de repetición en las vías urinarias, hematuria macroscópica total y dolor opresivo en la fosa renal derecha, por lo que se le realizó tomografía abdominopélvica contrastada que evidenció engrosamiento de la pelvis renal derecha con $11 \mathrm{UH}$ en fase simple y 67 UH en fase contrastada, disminución del diámetro de la pelvis, dilatación del cáliz superior y defecto de llenado en la pelvis renal en la fase de eliminación, sin estriación de la grasa perirrenal (Fig. 2). Se le realizó nefroureterectomía radical derecha con rodete vesical laparoscópico, con hallazgos macroscópicos con reporte de riñón de $9 \times 7 \times 4 \mathrm{~cm}$, sistema pielocalicial dilatado de $2.5 \times 1 \mathrm{~cm}$, con presencia en su interior de lesión de aspecto neoplásico, infiltración a la pared ureteral y tejido adiposo adyacente sin afectación del parénquima renal (Fig. 3). El reporte histopatológico fue de metástasis de carcinoma infiltrante sin patrón específico con afectación en pelvis renal y uréter, infiltración de la totalidad de la pared y del tejido adiposo adyacente con permeación vascular, el riñón con pielonefritis crónica leve y un quiste renal simple, uréter distal y rodete vesical sin datos de actividad tumoral (Fig. 4); y la inmunohistoquímica reportó receptor de estrógenos positivo, receptor de progesterona negativo, receptor del factor de crecimiento epidérmico tipo 2 negativo, CK 7 positivo y CK 20 negativo (Fig. 5). La paciente fue manejada con 


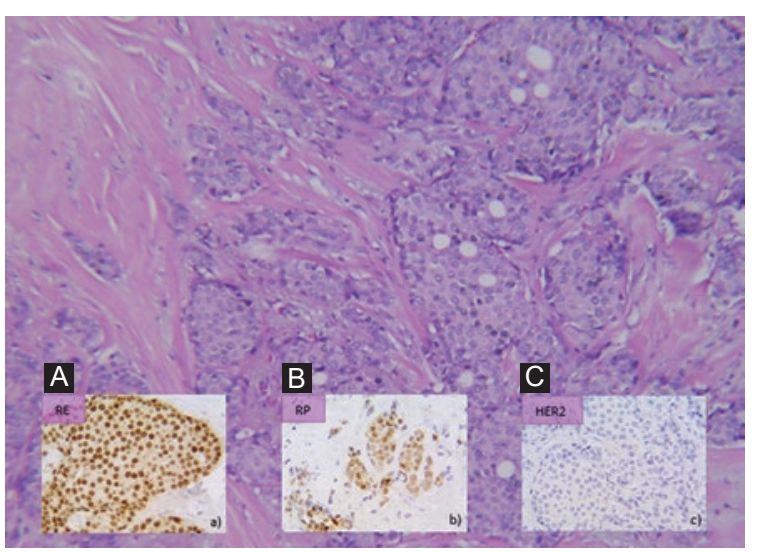

Figura 1. Carcinoma infiltrante sin patrón específico, células dispuestas en trabéculas con patrón infiltrante y estroma con reacción desmoplásica. A: tinción de inmunohistoquímica a receptor de estrógenos positivos. B: receptor de progesterona positivo. C: receptor del factor de crecimiento epidérmico tipo 2 negativo.

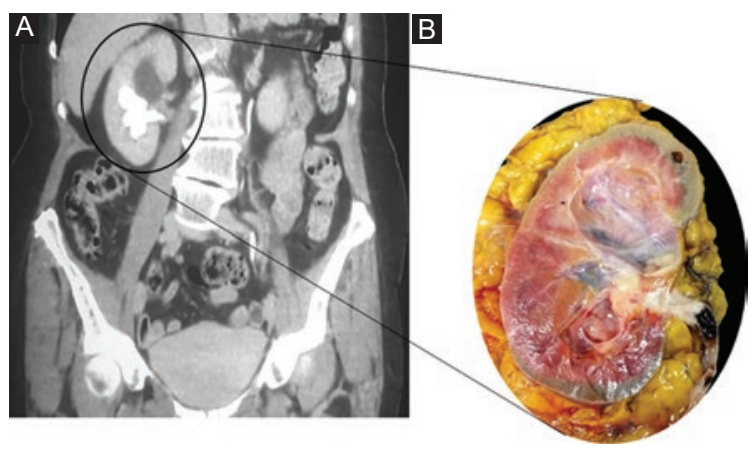

Figura 2. A: tomografía abdominopélvica contrastada con presencia de ectasia en cáliz superior y defecto de llenado en pelvis renal. B: imagen macroscópica de riñón derecho.

letrozol, $2.5 \mathrm{mg} / 24 \mathrm{~h}$ por vía oral, y se encuentra asintomática sin evidencia de recurrencia o progresión de la enfermedad inicial.

\section{Discusión}

La metástasis ureteral de cualquier tumor previo es extremadamente rara. En la literatura mundial se han reportado 342 casos $^{7}$. Suele ser asintomática y solo una tercera parte de los pacientes con recurrencia de la enfermedad reportan síntomas clínicos, lo que hace que esta enfermedad se detecte tardíamente.

El dolor lumbar, las náuseas, las infecciones de vías urinarias y la pérdida de peso se presentan en el $36 \%$ de los casos $^{8}$. Estos síntomas se relacionan con más frecuencia con otras enfermedades, como litiasis o infección de vías urinarias.
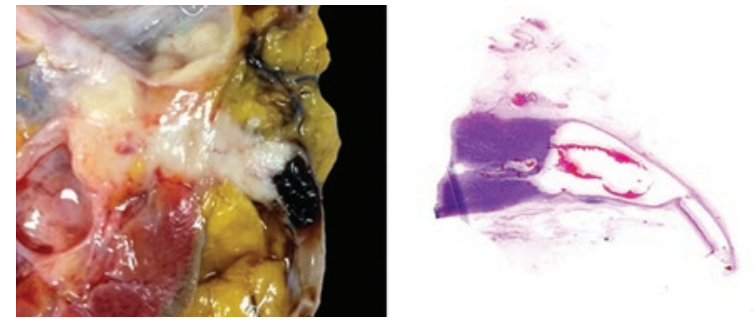

Figura 3. Imagen macroscópica y microfotografía de tumor infiltrando por debajo del urotelio la pared de la pelvis renal y el tejido adiposo adyacente.

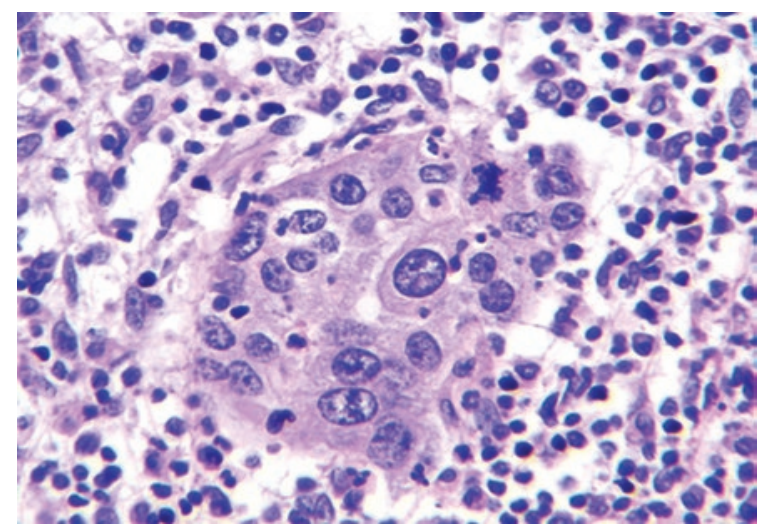

Figura 4. Microfotografía (H-E 400x) que muestra carcinoma infiltrante sin patrón específico.

La rareza de la metástasis del cáncer de mama hacia las vías urinarias radica en que los modelos de diseminación metastásica describen una compleja interacción, involucran intravasación y extravasación tumoral, circulación, proliferación, angiogénesis y el microambiente del tejido a metastatizar 9 .

El patrón de metastásis de carcinoma lobular infiltrante difiere significativamente del de carcinoma ductal infiltrante; tiende a ocurrir como un engrosamiento difuso de la mucosa en lugar de como un nódulo discreto ${ }^{10}$.

Además, el carcinoma ductal infiltrante a menudo metastatiza al pulmón, el hígado, el hueso y el cerebro, mientras que el carcinoma lobular infiltrante tiende a extenderse al tracto gastrointestinal o genitourinario, el peritoneo y el retroperitoneo, y las leptomeninges ${ }^{11}$.

La enfermedad con receptor hormonal positivo preferentemente metastatiza en el hueso como primer sitio, mientras que la enfermedad con receptor hormonal negativo se presenta con múltiples sitios de metástasis viscerales ${ }^{12}$. El cáncer de mama con receptores triple negativo generalmente recurre en los primeros años, mientras que la enfermedad con 


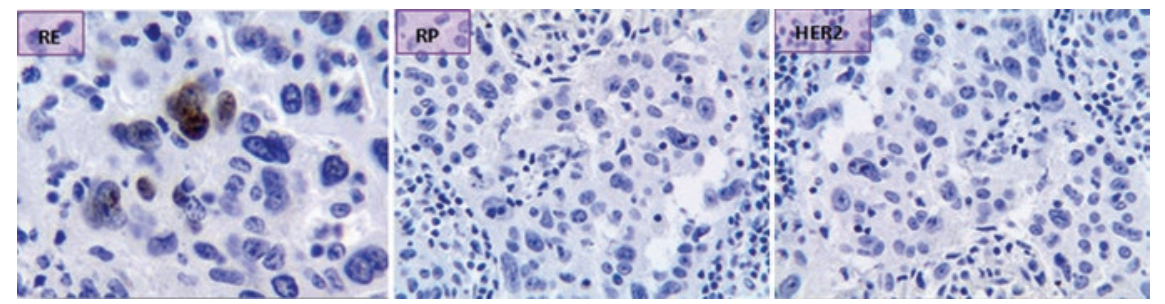

Figura 5. Inmunohistoquímica que muestra positividad del receptor de estrógenos (RE), negatividad del receptor de progesterona (RP) y negatividad del receptor del factor de crecimiento epidérmico tipo 2 (HER2).

receptor hormonal positivo está asociada con metástasis tardías después de la resección del tumor primario $^{13}$.

De las metástasis ureterales, el $7.8 \%$ provienen de cáncer de mama ${ }^{14}$; el resto, de otros órganos como el estómago, la vejiga y la próstata 7 . Sin embargo, otros autores refieren cifras más bajas. Brady, et al. ${ }^{15}$ reportan carcinoma de mama metastásico a riñón y uréter en un $0.13 \%$.

El pronóstico de la enfermedad metastásica depende del estado del receptor hormonal y es mejor cuando los receptores hormonales son positivos ${ }^{16}$.

Se concluye que las metástasis tardías del cáncer de mama al uréter y la pelvis son muy raras, pero se deben considerar cuando las pacientes tienen antecedente de cáncer de mama y presentan sintomatología similar a la que presentó esta paciente.

\section{Conflicto de intereses}

Los autores declaran no tener conflicto de interés.

\section{Responsabilidades éticas}

Protección de personas y animales. Los autores declaran que para esta investigación no se han realizado experimentos en seres humanos ni en animales.

Confidencialidad de los datos. Los autores declaran que han seguido los protocolos de su centro de trabajo sobre la publicación de datos de pacientes.

Derecho a la privacidad y consentimiento informado. Los autores han obtenido el consentimiento informado de los pacientes y/o sujetos referidos en el artículo. Este documento obra en poder del autor de correspondencia.

\section{Bibliografía}

1. Organización Mundial de la Salud. Cáncer de mama: prevención y control. Carga de cáncer de mama. (Consultado el 20 de octubre de 2017.) Disponible en: http://www.who.int/topics/cancer/breastcancer/es/index1. html

2. Ferlay J, Soerjomataram I, Dikshit R, Eser S, Mathers C, Rebelo M, et al. Cancer incidence and mortality worldwide: sources, methods and major patterns in GLOBOCAN 2012. Int J Cancer. 2015;136:359-86.

3. Soerjomataram I, Louwman MW, Ribot JG, Roukema JA, Coebergh JW. An overview of prognostic factors for longterm survivors of breast cancer. Breast Cancer Res Treat. 2008;107:309-30.

4. Grabstald $\mathrm{H}$, Sherman R. Radiographic diagnosis of ureteral involvement by metastatic breast cancer. Radiology. 1969;92:1184-7.

5. Lee YT. Breast carcinoma: pattern of metastasis at autopsy. J Surg Oncol. 1983;23:175-80.

6. Caskey $\mathrm{Cl}$, Scatarige JC, Fishman EK. Distribution of metastases in breast carcinoma: CT evaluation of the abdomen. Clin Imaging. 1991:15:166-71.

7. Haddad FS. Metastases to the ureter. Review of world literature, and three new case reports. J Med Liban. 1999;47:265-71.

8. Rigondet G, Sale JM, Lautier A. Secondary tumor of the ureter. Metastasis of breast carcinoma. Ann Urol. 1988;22:301-2.

9. Norton L, Massague J. Is cancer a disease of self-seeding? Nat Med. 2006;12:875-8.

10. Sanguedolce $F$, Landriscina $M$, Ambrosi A, Tartaglia N, Cianci $P$, Di Millo $M$, et al. Bladder metastases from breast cancer: managing the unexpected. A systematic review. Urol Int. 2018;101:125-31.

11. Borst MJ, Ingold JA. Metastatic patterns of invasive lobular versus invasive ductal carcinoma of the breast. Surgery. 1993;114:637-41.

12. Vona-Davis L, Rose DP, Gadiyaram V, Ducatman B, Hobbs G, Hazard H, et al. Breast cancer pathology, receptor status, and patterns of metastasis in a rural Appalachian population. J Cancer Epidemiol. 2014:2014:1-9.

13. Pagani O, Price KN, Gelber RD, Castiglione-Gertsch M, Holmberg SB, Lindtner $\mathrm{J}$, et al. Patterns of recurrence of early breast cancer according to estrogen receptor status: a therapeutic target for a quarter of a century. Breast Cancer Res Treat. 2009;117:319-24.

14. López-Martínez RA, Stock JA, Gump FE, Rosen JS. Carcinoma of the breast metastatic to the ureter presenting with flank pain and recurrent urinary tract infection. Am Surg. 1996;62:748-52.

15. Brady LW, O'Neill EA, Farber SH. Unusual sites of metastases. Semin Oncol. 1977;4:59-64.

16. Clark GM, Sledge GW Jr, Osborne CK, McGuire WL. Survival from first recurrence: relative importance of prognostic factors in 1015 breast cancer patients. J Clin Oncol. 1987;5:55-61. 